\title{
A festa magnífica no Porto para a cerimónia do Prémio da Crítica 2013
}

\section{Maria Helena Serôdio}

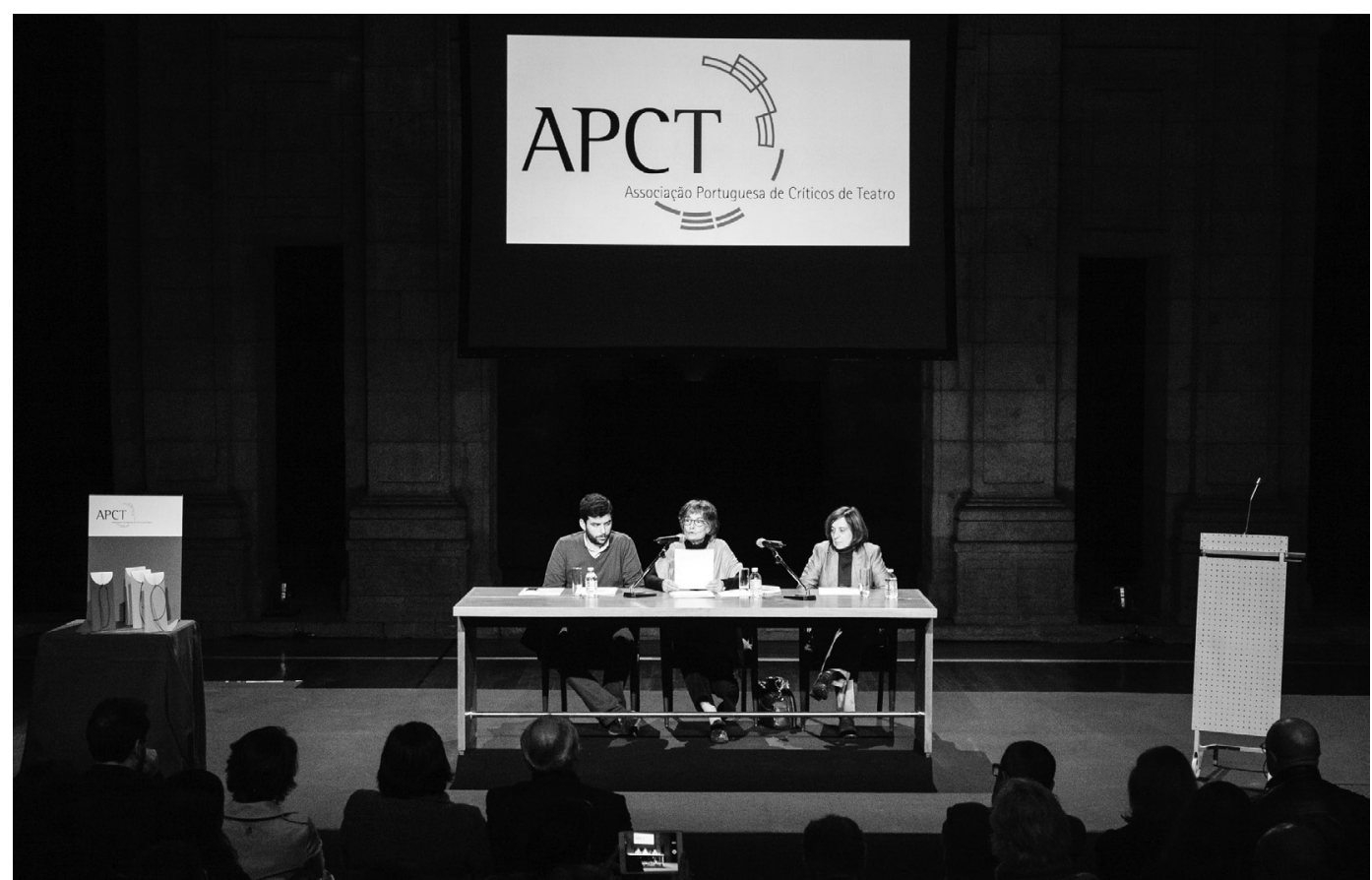

1.

Foi a primeira vez que a cerimónia do Prémio da Crítica se realizou na cidade do Porto... e já lá vão mais de dez anos que se vem cumprindo entre nós esta celebração anual ao teatro por parte dos críticos portugueses!

Não poderíamos ter tido um espaço mais belo e acolhedor para a breve formalidade simbólica - da atribuição desse Prémio - do que o claustro nobre do Mosteiro de São Bento da Vitória ("extensão" belíssima do Teatro Nacional São João), com a fabulosa equipa que acompanha o Director do TNSJ, o encenador Nuno Carinhas, que tão pronta e amavelmente acolheu a nossa sugestão.

Nesse esplêndido claustro - preparado para as diversas valências que o TNSJ tem sabido dinamizar - foi possivel apreciar o rigor técnico e o sentido artístico de um grupo de profissionais que é admirável até na paciência e disponibilidade com que acolhe os visitantes e os seduz - em termos absolutos - pela perfeição do trabalho que desenvolve e pelo prazer de que dá prova na exemplar observância desse cumprimento.
É ainda de aplaudir o modo como funciona a biblioteca e o seu importantíssimo Centro de Documentação, serviços que acompanham, de resto, a excelência do trabalho deste Teatro Nacional.

Agradecemos, por isso, muito sinceramente 0 acolhimento amável e generoso por parte da Direcção do Teatro Nacional São João, bem como o apoio inestimável, competentíssimo e discreto de toda a sua equipa - de criativos e técnicos - que nos proporcionaram uma tarde inesquecivel naquele dia 3 de Março, o dia que antecedeu a Terça-feira Gorda deste ano. De que - como é inevitável... - guardaremos memória grata por muito tempo! Até pelo privilégio raro de termos contado com uma cobertura fotográfica de excepção que o João Tuna tão generosamente nos cedeu.

E isto apesar da aflição - longa e não isenta de algum desespero - com que tivemos de aguardar a chegada ao Porto da camioneta em que vinham os artistas da Companhia de Teatro de Almada, bem como alguns representantes do Município e elementos do público mais 


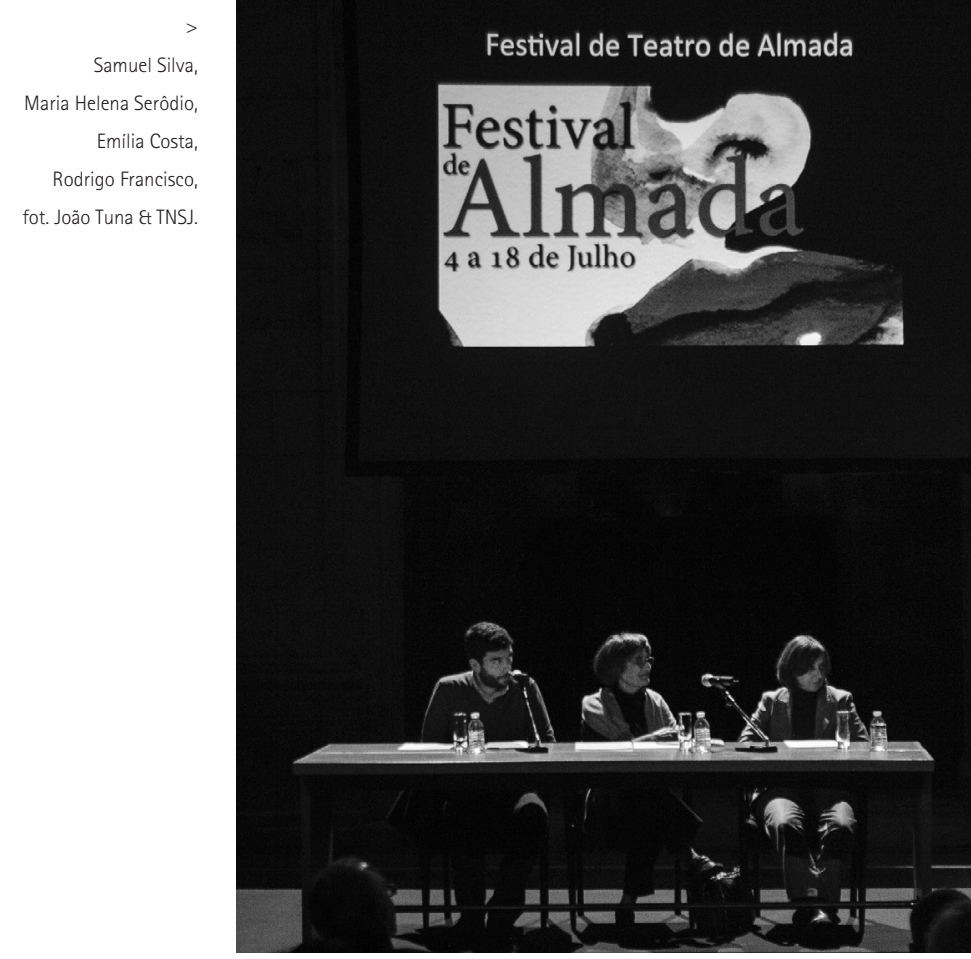

Festival de Teatro de Almada

Emilia Costa,

Rodrigo Francisco

fot. João Tuna \&t TNSJ.

aficionado. Em dia de chuva e com os constrangimentos de velocidade que aguardam uma camioneta de passageiros, não foi fácil cumprir o horário, pelo que se atrasou em muito o início da sessão. Mas, com inexcedive elegância e simpatia, ninguém do TNSJ deu o mais pequeno sinal de impaciência ou desagrado...

Pareceu-nos também importante incluir nesta secção da revista o texto que Rodrigo Francisco leu na cerimónia, endereçando as suas palavras - explicitamente - ao Director do Teatro Nacional São João, ao Presidente da Câmara Municipal de Almada, aos membros do Júri da APCT, bem como aos amigos, colegas e público do Festival presentes na sessão.

2.

Desde 2003, e em consequência de uma reorganização da Associação Portuguesa de Críticos de Teatro, foi criado o Prémio da Crítica numa modalidade muito sóbria e, por isso mesmo, mais rigorosa e exigente. Já não se contemplam as muitas valências que era usual distinguirem-se, optando a APCT por atribuir anualmente um só Prémio e apenas três Menções Especiais: em qualquer dos casos, abrindo-se a uma multiplicidade de premiáveis, o que tem permitido uma maior liberdade na distinção de artistas, textos, espectáculos, festivais, editoras, companhias, técnicos, criativos, etc., como se pode constatar na lista que publicamos no fim desta abertura do Dossiê Temático.

0 que acho também importante destacar, neste procedimento da APCT, é a obrigação de não nos limitarmos à frase curta que enviamos a quem recebe o Prémio e à imprensa em geral. De facto, enquanto APCT - e pela responsabilidade crítica que claramente assumimos -, julgamos importante explicar melhor as razões da escolha: primeiro em cerimónia pública e, depois, editando uma versão um pouco mais longa e argumentada dessa declaração na revista Sinais de cena, a revista semestral da APCT que em Junho e Dezembro de cada ano se publica em articulação com o Centro de Estudos de Teatro da Universidade de Lisboa, e que tem podido contar, desde o seu segundo número, com o apoio publicitário dos dois Teatros Nacionais: São João e D. Maria II. E estas são parcerias não apenas inestimáveis, mas também decisivas para que haja revista e para que os críticos de teatro - na sua associação - se sintam comprometidos a exprimir as razões pelas quais decidem destacar o melhor de cada ano no campo do teatro no seu sentido mais amplo.

Apesar de ter sido esta a primeira incursão nortenha que fizemos para a cerimónia do Prémio, foram muitos os artistas e os espectáculos do "Norte" (mas não só...) que a APCT tem - muito justamente - destacado ao longo destes últimos onze anos, como se comprova na listagem que esta introdução ao Dossiê regista em apêndice.

E já agora que, a propósito da sessão de atribuição do Prémio, falamos de geografia, gostaria de sublinhar que, relativamente aos premiados deste ano, três não são de Lisboa: é o caso do Festival de Teatro de Almada, que recebeu o Prémio da Crítica 2013, mas é também o caso do espectáculo Rei Lear, do Teatro Oficina e, como é evidente também, o do espectáculo Ah, os dias felizes, do TNSJ.

Para finalizar, e em nota muito pessoal mas breve, não pude deixar de recordar - durante a cerimónia - a última vez que tinha estado naquele belo Mosteiro de São Bento da Vitória: tinha sido a 11 de Novembro de 2009, na altura do lançamento de um importante livro sobre o teatro português (e irlandês) que resultava de uma brilhante tese de doutoramento apresentada à Faculdade de Letras da Universidade do Porto: Identidades reescritas: Figurações da Irlanda no teatro português. Foi seu autor uma personalidade notável da intelectualidade do Porto (e do pais), apesar de ser ainda muito jovem, e que teve um papel decisivo para a renovação da APCT. Refiro-me, naturalmente, ao Paulo Eduardo Carvalho, e não podemos deixar de o recordar sempre com uma grande ternura e uma infinita saudade. Porque, como muito poucos, viveu 


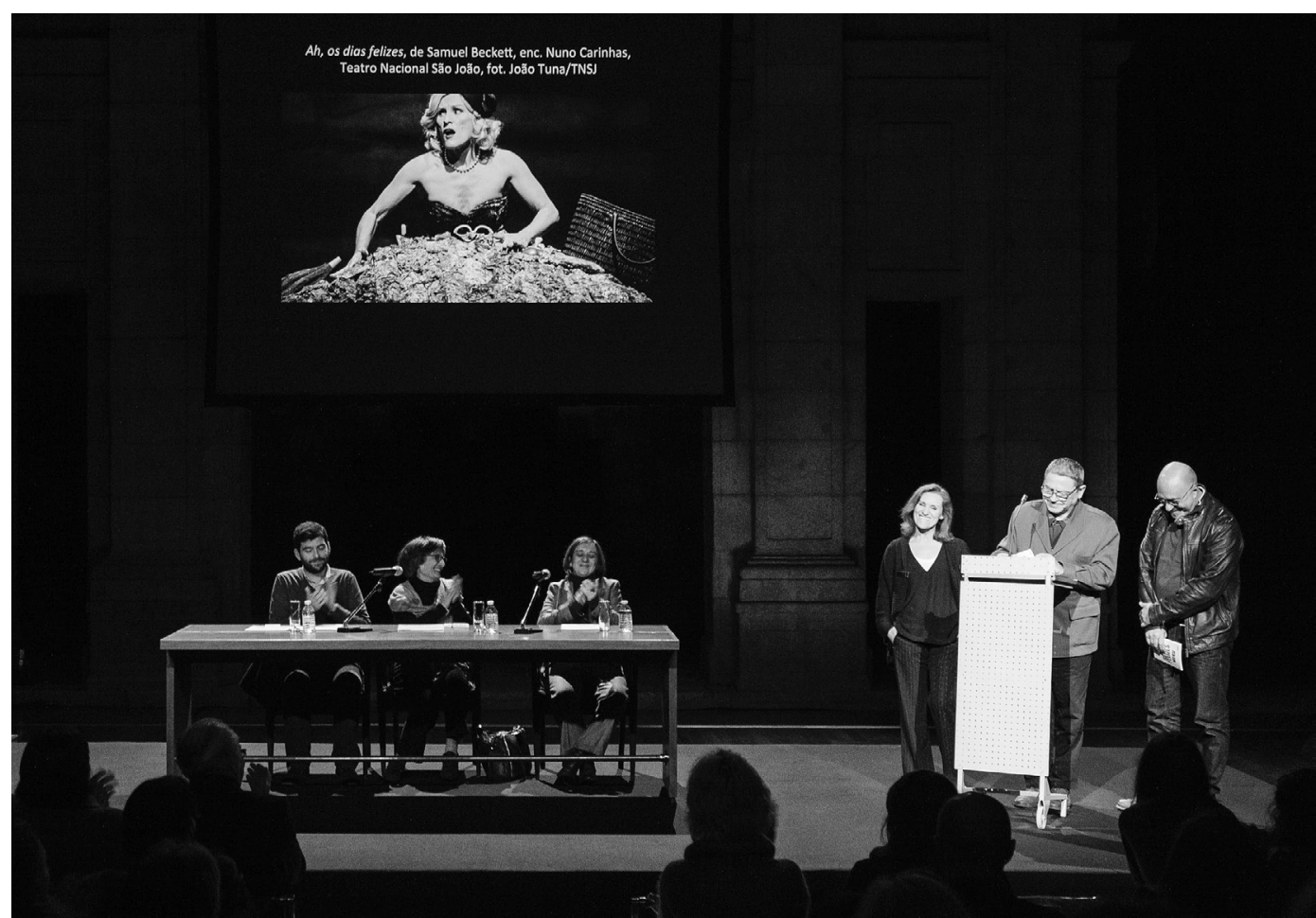

Samuel Silva,

Maria Helena Serôdio,

Emilia Costa,

Emilia Silvestre

Nuno Carinhas,

João Cardoso,

fot. João Tuna \& TNSJ.
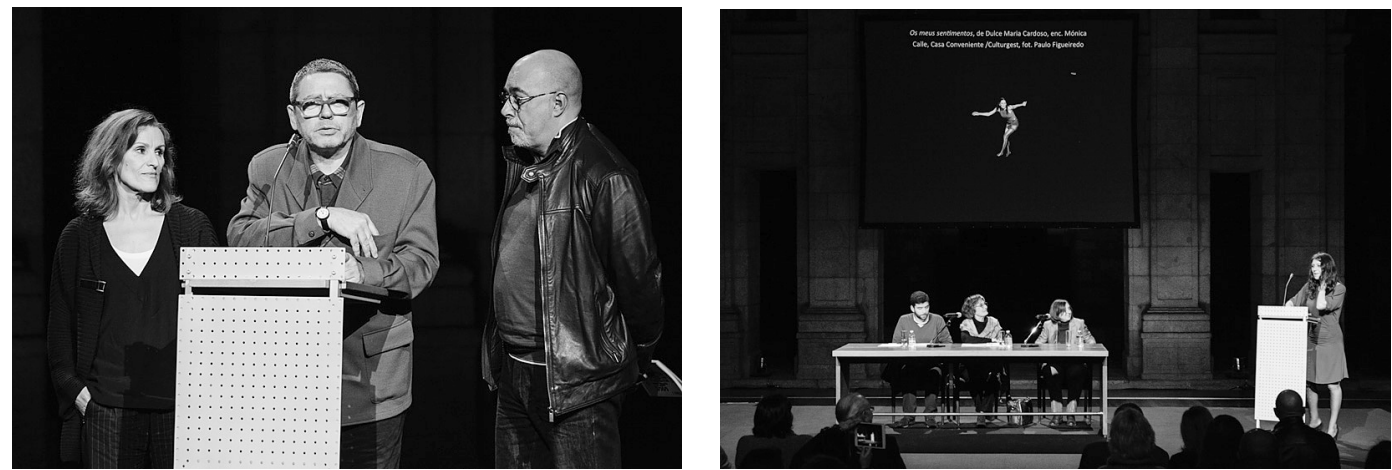

Emilia Silvestre, Nuno

Carinhas, João Cardoso, fot. João Tuna \& TNSJ.

Samuel Silva

Maria Helena Serôdio

Emilia Costa,

Mónica Calle,

de forma generosa, dedicando-se amorosamente a todos os que precisavam do seu conselho, do seu saber e da sua imprescindivel ajuda, sobretudo no campo da arte que mais o seduzia e a que se dedicou da forma mais apaixonada: justamente, o teatro.

Nesse ponto, e para concluir esta breve introdução, recordo a declaração que Nuno Carinhas afectuosamente escreveu no Manual de Leitura do espectáculo Ah, os dias felizes - uma das Menções Especiais deste ano - e que gostaria aqui de citar: "Ainda e sempre à memória de Paulo Eduardo Carvalho, nosso dedicado companheiro".

E sentimos todos que foi também por ele que estivemos ali na festa da atribuição do Prémio da Crítica relativo a 2013 !

Breve Historial do Prémio da Crítica

\section{3}

Júri: Ana Pais, Miguel-Pedro Quadrio, Mónica Guerreiro, Paulo Eduardo Carvalho, Rui Cintra.

Prémio: Vera San Payo de Lemos.

Menções Especiais: Percursos, do CPA do CCB || Circo, pelo Teatro da Garagem || Francisco Leal.

\section{4}

Júri: João Carneiro, Maria Helena Serôdio, Miguel-Pedro Quadrio, Mónica Guerreiro, Paulo Eduardo Carvalho Prémio: Para além do Tejo, pelo Teatro Meridional. Menções Especiais: 0 fazedor de teatro, pela Companhia de Teatro de Almada || A cabra, ou quem é Silvia?, pelo Teatro A Comuna || Luz/Interior, projecto de Rita Só (em colaboração com a Casa Conveniente).

\section{5}

Júri: João Carneiro, Maria Helena Serôdio, Sebastiana Fadda, Paulo Eduardo Carvalho.

Prémio: Ex-aequo: Um homem é um homem, pelo Teatro da Cornucópia, e Ubus, pelo Teatro Nacional S. João. Menções Especiais: Miguel Castro Caldas || Serviço d'amores, pelo Teatro Nacional D. Maria II e As Boas Raparigas || Elenco de Luz na cidade, pelo Teatro Aberto.

\section{6}

Júri: Ana Pais, João Carneiro, Jorge Louraço Figueira Maria Helena Serôdio, Rui Pina Coelho.

Prémio: Ex-aequo: interpretações de Maria João Luis (em Stabat Mater, pelos Artistas Unidos) e João Lagarto (em Começar a acabar, pelos Crónicos, ACE e TNSJ). 


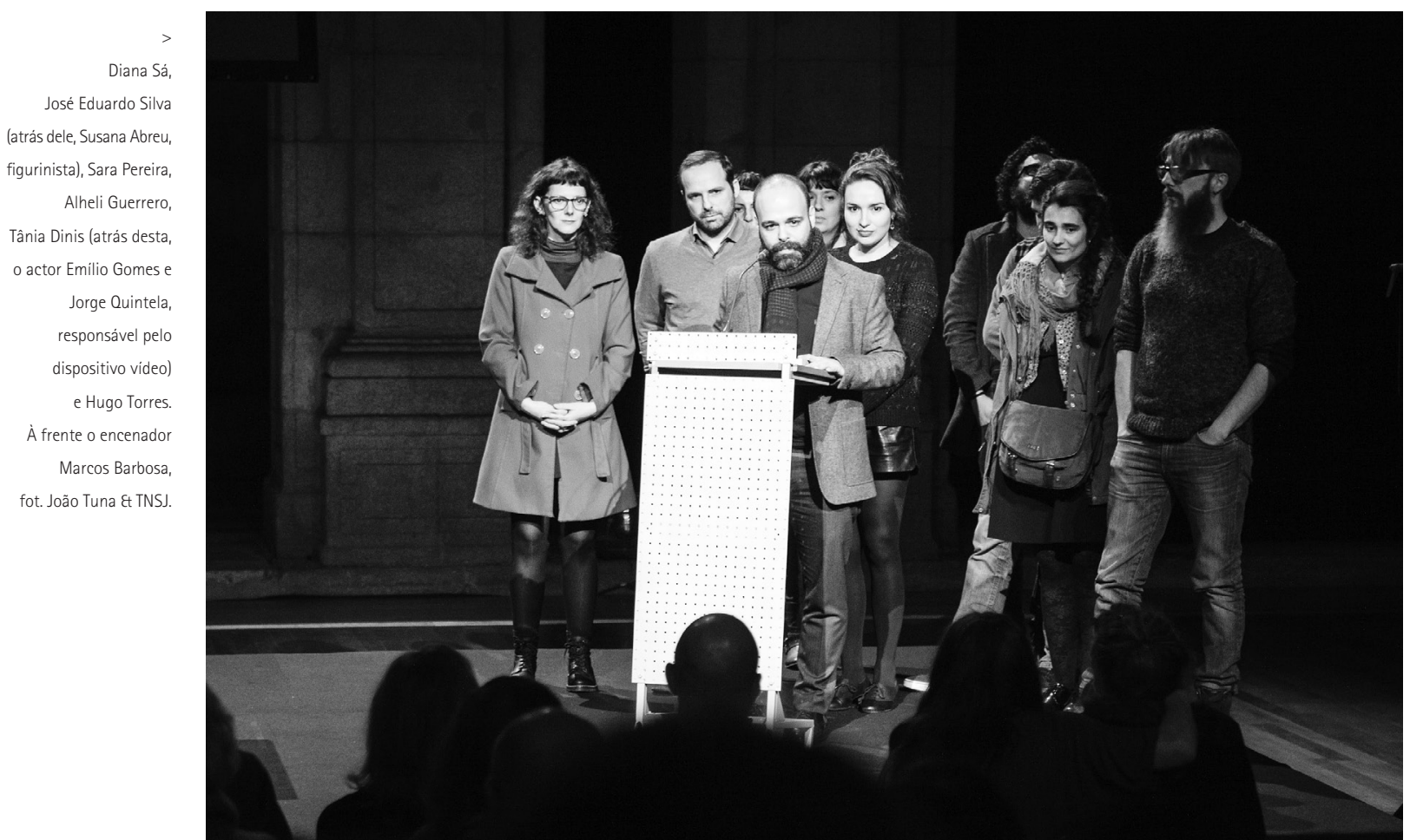

Menções Especiais: Patrícia Portela: dramaturgia da Trilogia Flatland || João Mota: concepção cénica de Todos os que caem || Fernando Mota: música e espaço sonoro de Por detrás dos montes.

\section{7}

Júri: Ana Pais, Constança Carvalho Homem, João Carneiro Maria Helena Serôdio, Rui Pina Coelho.

Prémio: Ex-aequo: A tragédia de Júlio César, pelos Teatro da Cornucópia e São Luiz Teatro Municipal, e Foder e ir às compras, pelos Primeiros Sintomas e Centro Cultural de Belém.

Menções Especiais: Emília Silvestre || Iniciativa Panos da Culturgest || Livros Cotovia.

\section{8}

Júri: Ana Pais, Constança Carvalho Homem, João Carneiro, Maria Helena Serôdio, Rui Pina Coelho.

Prémio: João Brites, Saga: Ópera extravagante.

Menções Especiais: Carla Galvão || Nuno Cardoso, Platonov || Miguel Loureiro, Juanita Castro.

\section{9}

Júri: Alexandra Moreira da Silva, Constança Carvalho Homem, João Carneiro, Rita Martins, Rui Pina Coelho. Prémio: Jorge Silva Melo pela encenação de Esta noite improvisa-se e Seis personagens à procura de autor, sobre textos de Luigi Pirandello.

Menções especiais: Bernardo Monteiro || colectivo Casa Conveniente, na pessoa de Mónica Calle.

\section{0}

Júri: Alexandra Moreira da Silva, João Carneiro, Maria Helena Serôdio, Rui Pina Coelho (/Paulo Eduardo Carvalho). Prémio: FIMFA (Festival Internacional de Marionetas e Formas Animadas) || João Paulo Seara Cardoso (Teatro de Marionetas do Porto).
Menções especiais: Miguel Guilherme em Osenhor Puntila e o seu criado Matti) || Elenco de As Boas Raparigas em Mulheres profundas | Animais superficiais || Luis Castro, Karnart, em Húmus.

\section{1}

Júri: Alexandra Moreira da Silva, Constança Carvalho Homem, João Carneiro, Maria Helena Serôdio, Rui Monteiro. Prémio: Comédias do Minho.

Menções especiais: Gonçalo Amorim ( 0 jogador, Do alto da ponte, Já passaram quantos anos, perguntou ele) II Ciclo Müller, Casa Conveniente || Teatro do Vestido.

\section{2}

Júri: Alexandra Moreira da Silva, João Carneiro, Jorge Louraço Figueira, Maria Helena Serôdio, Rui Monteiro. Prémio: Rogério de Carvalho, pela encenação de 0 doente imaginário, de Molière, e Devagar, de Howard Barker. Menções especiais: João Tuna || Juramentos indiscretos, pelo Teatro dos Aloés || Salomé, pelos Primeiros Sintomas. 